Revista

Actualidades Investigativas

en Educación

\title{
Competencias ciudadanas: una reconstrucción conceptual en el marco de la Educación Cívica costarricense
}

Citizenship competencies: a conceptual reconstruction within the framework of the Costa Rican Civic Education

\author{
Volumen 19, Número 2 \\ Mayo-Agosto \\ pp. 1-20
}

Henry Arce Ramírez

Cite este documento así

Arce Ramírez, Henry. (2019). Competencias ciudadanas: una reconstrucción conceptual en el marco de la Educación Cívica costarricense. Revista Actualidades Investigativas en Educación, 19(2), 1-20. Doi. 10.15517/aie.v19i2.36904 


\title{
Competencias ciudadanas: una reconstrucción conceptual en el marco de la Educación Cívica costarricense \\ Citizenship competencies: a conceptual reconstruction within the framework of the Costa Rican Civic Education
}

\section{Henry Arce Ramírez ${ }^{1}$}

\begin{abstract}
Resumen: Este ensayo presenta la conceptualización de las competencias ciudadanas dentro del contexto educativo costarricense, mediante el análisis de posturas teóricas y prácticas de diferentes autores y una valoración del abordaje que se realiza en la dimensión de competencias ciudadanas del programa de estudio de Educación Cívica 2009. El propósito es generar espacios de reflexión de la propuesta planteada por el Ministerio de Educación Pública con relación a las competencias para la participación ciudadana activa y la convivencia democrática, así como, el impacto positivo que tienen para el fortalecimiento de la calidad de vida del estudiantado y la sociedad en general. Entre las principales conclusiones de este trabajo se destaca la coherencia que tiene la propuesta de competencias ciudadanas con los referentes teóricos y metodológicos analizados, la importancia de la mediación pedagógica, la responsabilidad de los docentes en la formación integral del estudiantado y la necesidad de ampliar este tipo de aprendizajes ciudadanos en todas las asignaturas del currículo nacional.
\end{abstract}

Palabras clave. educación cívica, competencias ciudadanas, participación ciudadana, convivencia democrática.

\begin{abstract}
This essay presents a conceptualization of the civic competencies inside the Costa Rican educational context by means of an analysis of theoretical and practical positions from different authors. This evaluation of the approach performed in the dimension of the civic competencies program of the 2009 study of Civic Education, is to generate spaces to reflect on the proposed plan of the Ministry of Public Education in relationship to the competencies for the active participation and the democratic coexistence that will strengthen the quality of life of the students in society, thus making a positive impact in their lives. The main conclusions of this work emphasize the coherence of the proposal of civic skills/competencies within the analyzed theoretical and methodological modality, the importance of pedagogic mediation, the responsibility of teachers in the integral formation of the students, and, the need to extend this type of civic teaching and learning in all subjects of the curriculum.
\end{abstract}

Keywords. civic education, citizenship competencies, citizen participation, democratic coexistence.

\footnotetext{
1 Asesor Nacional de Estudios Sociales en la Dirección de Gestión Evaluación de la Calidad del Ministerio de Educación Pública, Costa Rica.
}

Dirección electrónica: henry.arce.ramirez@mep.go.cr

Ensayo recibido: 30 de octubre, 2018

Enviado a corrección: 22 de enero, 2019

Aprobado: 11 de marzo, 2019 


\section{Introducción}

La educación es una de las actividades más beneficiosas del ser humano, pues de ella depende su desarrollo; se le considera una acción inherente a la evolución socioeconómica, en tanto permite la promoción de la inteligencia, así como las destrezas y habilidades para la vida. Además, facilita la transmisión de valores, costumbres, ideas, conocimientos y formas de vivir, lo cual ha generado la necesidad de concebir procesos educativos integrales para reproducir patrones culturales y ciudadanos orientados al mejoramiento de la convivencia en sociedad.

La Educación Cívica en Costa Rica se consideró, durante muchos años, una asignatura más del currículo nacional, sin resaltar el valor de la formación ciudadana y su impacto en la sociedad. Lo manifestado anteriormente se evidencia en el desarrollo de lecciones de Educación Cívica, donde la enseñanza y el aprendizaje muchas veces se visualizan como simples procesos de transmisión de contenidos políticos sin sentido para el estudiantado; es decir, una asignatura inerte y mecanizada.

En tal modo, es claro que dicha concepción de la asignatura no favorece el acercamiento a la práctica ciudadana ni aporta sustento a la formación para vivir y convivir. Al respecto, el Ministerio de Educación Pública (2005, p. 13) destaca que "de la calidad de la enseñanza de la formación ciudadana que se imparta en Costa Rica depende la calidad de la ciudadanía que regirá el presente y futuro del país".

Desde el 2009, el Ministerio de Educación Pública (MEP) implementó el programa de estudio de la asignatura de Educación Cívica "Ética, Estética y Ciudadanía", con la finalidad de brindarle al estudiantado una formación ciudadana activa, integral y contextualizada; este planteamiento curricular desarrolla aprendizajes para el ejercicio de la ciudadanía en el sistema educativo, a través de tres dimensiones: la cognitiva, la formativa y las competencias. Al respecto, es oportuno indicar que, entre los contenidos del programa, el aprendizaje de las competencias ciudadanas constituye una acción indispensable para lograr una formación que contribuya a fortalecer la democracia.

\section{Importancia de la educación en el sistema democrático costarricense}

Los orígenes de la democracia costarricense se remontan al periodo colonial, cuando los criollos buscaron alcanzar derechos en una sociedad exclusiva para los españoles. En buena medida, esta clase social fue motivada por los cambios ocurridos en Francia a través 
de la Revolución Francesa y la Declaración de los Derechos del Hombre y del Ciudadano, lo que forjó en las provincias de América la ilusión de la emancipación. De tal manera, la experiencia educativa de Francia como facilitadora del proceso de organización social y política, hizo que los primeros líderes políticos del país canalizaran la educación como un patrón por emular para lograr el empoderamiento del sistema democrático costarricense.

Por lo anterior, la formación del Estado costarricense en la primera mitad del siglo XIX se sustentó en un sistema político basado en posiciones teóricas de los pensadores liberales, donde la educación, precisamente, jugó un papel preponderante en el establecimiento de dicho modelo político y, por tanto, en el desarrollo del incipiente Estado costarricense. En relación con el contexto descrito, Palacios reafirma lo siguiente:

En la medida en que la experiencia política de la clase dirigente se arraigaba en el régimen político liberal democrático, la escuela adquirió importancia como mejor instrumento para formar la conciencia cívica y preparar para el ejercicio de la ciudadanía. (2005, p. 35)

En la misma línea constitutiva, es importante destacar la función que ha ejercido la educación en el proceso de socialización y que, a su vez, ha dado respaldo al sistema democrático. Al respecto, Palacios menciona que las decisiones educativas de la época fueron:

(...) un paso importante en el proceso de transformaciones políticas, económicas, sociales e ideológicas que conducirán a la formación, desarrollo, consolidación, y expansión del Estado Costarricense. Desde ese momento, surgió, en el discurso, un interés muy marcado por la educación y el papel socializador en que esta se puede desempeñar. (2005, p. 1)

El desarrollo de un marco jurídico para la educación demuestra fortaleza en torno al sentido de democracia que ha prevalecido en las aspiraciones del Estado costarricense. Esto se evidenció desde el año 1886, en el contexto de la Reforma Educativa de Mauro Fernández, con la promulgación de la Ley General de Educación Común, la cual declaraba explícitamente la democratización de la educación costarricense; con ello, propició ordenamiento y estructura al sistema educativo (Dengo, 2006). 
En la segunda mitad del siglo XX, otro suceso relevante también vino a robustecer la fórmula que establece la relación entre educación y democracia: la emisión de la Ley Fundamental de Educación: Ley № 2160 del año 1957. En ella se suscribe una declaración teleológica de clara extracción democrática, inspiración ideológica social que permite discutir sobre los procesos de transformación de la sociedad. (Dengo, 2006). La democracia en Costa Rica, es entendida como un sistema político que permite la organización, la legitimidad y el desarrollo de la vida del Estado, sin embargo, este ha trascendido y evolucionado hacia un modelo que permite a los ciudadanos tener influencia directa al favorecer espacios de representación, participación y la asociación en los ámbitos nacional, local, comunitario y en general, en la convivencia.

A pesar del gran camino recorrido por el Estado costarricense en la vida democrática, existen entre la población algunas deficiencias conceptuales sobre la democracia y sus espacios operativos, lo que, en consecuencia, limita el accionar ciudadano. Ante esta situación, es oportuno mantener espacios de reflexión y discusión constante que permitan replantear la formación de la ciudadanía en la actualidad y el papel que juega la educación en este menester. Delors (1996, p. 61) señala que es importante buscar "una relación sinérgica entre la educación y la práctica de una democracia participativa, además de preparar a cada individuo para el ejercicio de sus derechos y deberes, conviene recurrir a la educación permanente para edificar una sociedad civil activa".

El significado de la palabra democracia es simplificado como el acercamiento a las urnas electorales cada cuatro años, o bien, limitado a las acciones propias de los políticos tradicionales; es decir, se dimensiona únicamente como un sistema político estático y no como un medio de organización de la vida en una sociedad. De hecho, algunos autores reproducen dicha concepción, cuando señalan que,

(...) la democracia en tanto régimen político y en un sentido estricto, se refiere al conjunto de reglas, normas, y procedimientos a través de los cuales la mayor parte de los y las ciudadanas, participan del debate de los asuntos públicos, para elegir el gobierno y sus representantes o para promulgar la adopción de definiciones políticas. (Centro de Estudios y Publicaciones [CEP], 2003, p. 16)

Tal abordaje no resulta inclusivo, pues solo grupos específicos de la sociedad participan de esos procesos políticos. Por ello, es necesario anteponer a estas 
conceptualizaciones de democracia una posición teórica que permita dimensionarla como un conjunto de comportamientos que favorecen la convivencia en sociedad y de los cuales se establece la dirección en la que se organiza el Estado y la Nación. Esta noción de democracia está muy relacionada a la idiosincrasia, comprendida por los principios, los valores como la libertad, la igualdad, la tolerancia y el respeto a la legalidad que constituyen un Estado democrático y son materializados dentro de una sociedad para el bienestar de la colectividad (Trejos y May, 2001, p. 29).

La realidad de la democracia costarricense va más allá del sufragio y del establecimiento del marco jurídico; se debe comprender como una forma de vida que abre espacios para la ciudadanía mediante mecanismos como la participación y la representación, los cuales permiten la construcción y transformación de la sociedad. Trejos y May (2001) afirman que la democracia "se trata de una forma de vivencia y convivencia humana que no es perfecta pero sí perfectible y que ha demostrado, hasta ahora, ser la manera más civilizada de forma de gobierno" (p. 29).

Desde esta concepción, se percibe la democracia como un proceso de amplitud sin reducción a procedimientos formales de la institucionalidad costarricense, por lo que se puede comprender bajo un criterio de integralidad, con un sentido de participación de la ciudadanía; a saber, la concreción real del denominado "poder del pueblo". El sistema político al que se aspira, implica el respeto por los derechos humanos, la participación directa de las organizaciones sociales, el pluralismo y el diálogo; se concreta, de tal manera, que la democracia es una forma de organizar la convivencia social en una sociedad determinada (CEP, 2003, p. 54).

En el informe del Centro Centroamericano de Población titulado Cultura política de la democracia en Costa Rica: 2006 (Vargas-Cullell, Rosero-Bixby y Seligson, 2006, p. 132) se puede dimensionar la democracia desde tres aristas, las cuales permiten ampliar este concepto y clarificar el accionar de la ciudadanía en una sociedad democrática: una primera dimensión dirigida a la elección de sus gobernantes mediante el sufragio; la segunda la visualiza como la forma de gobierno que incluye las normas, instituciones y actos relacionados con el ejercicio del poder; finalmente, una tercera dimensión de convivencia ciudadana que corresponde a las acciones horizontales entre los ciudadanas.

De tal manera, el ejercicio de la ciudadanía es un aspecto de imperativa consideración en los diseños curriculares de las asignaturas, especialmente de la Educación Cívica, debido 
a las implicaciones que tiene sobre las prácticas y comportamientos de los seres humanos y la búsqueda del fortalecimiento del sistema democrático. Escámez y Gil (2002, p. 9) advierten que "la ciudadanía es conceptualizada como la relación social que vincula entre sí a los miembros de una comunidad política y se manifiesta mediante la participación en las instituciones de la sociedad y en las estructuras de decisión sobre los asuntos comunes".

En cuanto al concepto de ciudadanía, su abordaje suele limitarse de forma semejante a la noción de democracia, puesto que se orienta casi exclusivamente al ejercicio de los deberes políticos, sin profundizar una conceptualización más amplia. Según esta posición, "la ciudadanía es primariamente una relación política entre un individuo y una comunidad política, en virtud de lo cual el individuo es miembro de pleno derecho de la comunidad y le debe lealtad permanente" (Cortina, 2001, p. 39); como se observa, dicha percepción no empodera al ciudadano para hacer uso de sus derechos y deberes en función de buscar calidad de vida, no incentiva a buscar espacios de participación y representación para fortalecer la sociedad democrática y, como punto crítico, no favorece la convivencia social.

Para ejercer la ciudadanía de forma activa, se debe migrar de la idea de participación ciudadana como sinónimo únicamente de participación electoral a una concepción amplia e integral, fundamentada en la intervención consciente y responsable en los espacios de decisión de los asuntos públicos, con la perspectiva de instaurar una sociedad lo más democrática, libre y justa posible (CEP, 2003, p. 17). En tal modo, es necesario pensar en una ciudadanía que trascienda de la representación como mecanismo político a un sistema de participación real. Costa Rica es un país con una tradición política-democrática envidiable en América Latina, pero con deficiencias en la formación de sus habitantes para ser ciudadanos activos y conscientes de las responsabilidades y compromisos con la sociedad.

\section{Competencias en los espacios educativos: percepciones teóricas y antecedentes}

La noción de competencias tiene sus orígenes en la filosofía griega, especialmente en las teorías de Aristóteles referidas a la potencia y el acto, cuando se menciona que los seres humanos poseen facultades que pueden ser expresadas y ejecutadas. En la sociedad contemporánea, el término "competencia" tuvo su aparición en la década de 1970, a partir de las posiciones teóricas del filósofo y lingüista Noam Chomsky, expuestas en su obra "Competencia Lingüística” (Niño, 2008). 
Luego de los aportes de Chomsky, la noción de competencias tuvo auge en el ámbito empresarial en las décadas de 1970 y 1980, al definir los perfiles de personas capaces de realizar tareas concretas de forma eficiente. En este campo, David McClelland, citado por García y Saban (2008), aportó explicaciones relacionadas al desempeño por competencias en espacios laborales y profesionales, con la finalidad de mejorar los procesos de productividad y la eficiencia del trabajo.

Para comprender las principales acepciones de este concepto, es necesario referirse a su constitución etimológica; se trata de un vocablo derivado del latín y formado por dos palabras: cum y petere, que significan capacidad para construir (García, 2011). Las competencias consisten en la articulación de los conocimientos y las habilidades que permiten al ser humano llevar a cabo acciones que faciliten el logro de objetivos individuales y colectivos; además, se constituyen como componentes de carácter funcional, que se desarrollan en espacios concretos. Por su parte, Tobón (2007, p. 17) realiza aportes importantes al concepto de competencia, definiéndolas como:

Procesos complejos de desempeño con idoneidad en determinados contextos, integrando diferentes saberes (saber ser, saber hacer, saber conocer y saber convivir), para realizar actividades y/o resolver problemas con sentido de reto, motivación, flexibilidad, creatividad y emprendimiento, dentro de una perspectiva de procesamiento meta cognitivo, mejoramiento continuo y compromiso ético.

En la década de 1990, el desarrollo de las competencias se empezó a utilizar en el ámbito educativo, porque los sistemas de enseñanza tradicionales resultaron insuficientes para alcanzar procesos de aprendizajes significativos. De esta forma, surgió como un nuevo enfoque curricular para dar sentido práctico al conocimiento, el cual, además, tuvo buena acogida en diferentes países y organismos internacionales como la Organización de las Naciones Unidas para la Educación, la Ciencia y la Cultura (UNESCO). Este modelo propone el desarrollo de saberes aplicados a la formación integral del estudiantado para vivir en sociedad: aprender a conocer, aprender a hacer, aprender a ser y aprender a convivir.

El surgimiento del enfoque del currículo por competencias tiene como antecedente la teoría del aprendizaje derivada de la psicología cognitiva, la cual analiza los procesos mentales que implican la adquisición del conocimiento, donde se conciben los aprendizajes como "saberes de ejecución". Desde esta perspectiva teórica, las competencias constituyen 
un saber aplicado, donde se busca que el estudiantado adquiera saberes para desarrollarse de forma responsable e integral, mediante aprendizajes como saber pensar, saber desempeñarse, saber interpretar, saber comunicarse, saber tomar decisiones, entre otros (Argudín, 2005).

En las últimas décadas, las competencias han sido adaptadas a los ámbitos educativos y transforman de forma significativa los espacios de enseñanza y aprendizaje. En consecuencia, su abordaje en los sistemas educativos promueve en el estudiantado una serie de conocimientos, habilidades y destrezas que den respuesta a los problemas que enfrenta en la vida; dichas capacidades se proponen en los currículos a través de la interrelación de componentes actitudinales, procedimentales y conceptuales (Zabala y Arnau, 2007).

Este ensayo parte del concepto de competencias ciudadanas planteado en el Programa de Estudios de Educación Cívica vigente, el cual las define de la siguiente manera:

Un conjunto integrado de conocimientos, capacidades y destrezas que abren la posibilidad de actuar como ciudadano y ciudadana desde una perspectiva ética. La característica central de estas competencias ciudadanas es que son integradoras, es decir, que requieren al mismo tiempo elementos cognitivos y formativos, así como habilidades específicas y facultades de reflexión que se articulan en las acciones ciudadanas. (MEP, 2009, p. 187).

A partir de la concepción anterior, es posible deducir que este tipo de aprendizajes favorece la construcción de ambientes democráticos, el desarrollo capacidades para el manejo adecuado de los conflictos y el reconocimiento pleno de los derechos humanos; es decir, este tipo de formación integral fortalece el clima escolar y, en general, las habilidades de los estudiantes para vivir y convivir dentro y fuera de la comunidad educativa.

\section{Conceptualización de las competencias ciudadanas}

Es necesario formar a ciudadanos "capaces de reclamar sus derechos debidos y asumir las propias responsabilidades y deberes en orden a construirlos viviendo con los demás según los valores democráticos" (Escudero y Flecha, 2005, p. 8). Dentro de los 
sistemas políticos democráticos existe una relación importante entre la educación y la promoción de los aprendizajes ciudadanos. Gimeno y Henríquez (2001, p. 14) indican que,

(...) el centro escolar y más concretamente el aula puede convertirse en laboratorios para el análisis de cuestiones vinculadas con la actuación social y ciudadana de los propios alumnos y profesores. Se puede reflexionar sobre situaciones e incidentes que se producen a diario, analizarlos en profundidad y derivar conclusiones formativas de los mismos. Se puede trabajar en torno a situaciones y conflictos tomados de la vida real, propios de la comunidad local, autónoma, nacional o internacional, vividos directa o indirectamente, conocidos a través de los medios de comunicación social.

El aprendizaje para la ciudadanía debe ser conceptualizado desde las vivencias de los estudiantes y la comprensión de las diferentes situaciones a las cuales se enfrentan día con día. Según Alfaro y Badilla (2007, p. 13), "la educación para la ciudadanía debe desarrollarse desde lo cotidiano, el diálogo participativo y democrático, el respeto por la dignidad humana, la no discriminación y el respeto a la diversidad". Por lo tanto, este tipo de aprendizaje no puede ser planificado en el currículo como un contenido aislado de la realidad, ya que trasciende los libros de texto, las aulas, las asignaturas y el centro educativo. Dicha experiencia de aprendizaje debe ser orientada hacia el accionar dinámico y proactivo del desarrollo y el bienestar socio-político; estas competencias permiten direccionar los procesos de formación ciudadana hacia capacidades para construir dentro de una sociedad democrática (García, 2008).

Los aprendizajes para el ejercicio ciudadano buscan la transferencia de los conocimientos adquiridos a situaciones de la vida real, por lo que “(...) exige relacionar, interpretar, inferir, interpolar, inventar, aplicar, transferir los saberes a la resolución de problemas, intervenir en la realidad o actuar previendo la acción y sus contingencias" (Andrade, 2005, p. 1); lo expuesto evidencia la importancia de la reflexión permanente del entorno democrático para la formación y fortalecimiento de los aprendizajes ciudadanos.

Es este sentido, la concepción de competencia de Perrenoud (2002), citada por Andrade (2005, p. 1), enfatiza la necesidad de la formación de estos aprendizajes en entornos determinados, al definirlos como la “(...) capacidad de actuar de manera eficaz en un tipo definido de situación, capacidad que se apoya en conocimientos pero no se reduce a ellos"; esto resalta la relevancia de la relación existente entre la teoría y la práctica. 
Asimismo, el aprendizaje ciudadano en esta vinculación se entiende "como el conjunto integrado de conocimientos, capacidades y destrezas que abren la posibilidad de actuar como persona ciudadana en contextos democráticos" (MEP, 2009, p. 33).

Por su parte, Andrade (2005, p. 6) define la competencia como “(...) un saber hacer en la práctica, pero motivado en un aprendizaje significativo que se transfiere a situaciones de la vida real y que implica la resolución de problemas en la práctica". Esto permite comprender que el aprendizaje ciudadano no puede ser desarrollado desde una posición conductista, mecánica y estática; por el contrario, debe fundamentarse en la teoría cognitiva del aprendizaje, de manera que permita potenciar la adquisición de procesos metacognitivos, experienciales y creativos para accionar satisfactoriamente en el contexto democrático (Villarini, 1996). La concepción de aprendizaje para el ejercicio ciudadano abordada en este ensayo considera dos aspectos esenciales de este enfoque formativo: participación activa y convivencia democrática.

La participación activa es conceptualizada por Instituto de Formación y Estudios en Democracia del Tribunal Supremo de Elecciones (IFED-TSE) como la conformación de "grupos de ciudadanas y ciudadanos organizados que realizan actividades formales e informales para desarrollar proyectos, cambiar políticas, generar discusión, proteger derechos, hacer denuncias, ejercer control; en general, para mejorar la calidad de vida de las personas" (2012, p. 26). Lo anterior orienta una perspectiva de la participación ciudadana que trasciende la representatividad política y el proceso electoral; en este aspecto, los espacios cotidianos para el ejercicio ciudadano se convierten en una oportunidad para fortalecer el sistema político y mejorar la sociedad costarricense mediante sus constantes intervenciones en la toma de decisiones.

En la misma línea, otros autores como Guillén, Sáenz, Badii y Castillo (2009) señalan que el término participación es:

(...) utilizado para explicar la incidencia de los individuos y grupos sociales en las diferentes etapas en las que se resuelven asuntos de interés público, es decir, en la consulta, discusiones, planteo de propuestas, y todo tipo de actividades que en las cuales interrelacionan el Estado y los ciudadanos para el progreso de la comunidad. (p. 179) 
En cuanto a la noción de convivencia democrática, la UNESCO (2009), la define como un medio para:

(...) mejorar las relaciones humanas, resolver conflictos o prevenir contra la violencia o el fracaso escolar, pero son, sobretodo, un fin primordial de la acción educativa y misión de la escuela. De este modo, una tarea principal de la escuela es generar y sostener una coherencia progresiva entre sus principios, sus propósitos educativos y sus prácticas cotidianas. (p. 17)

Esta concepción otorga gran relevancia a la tarea de la escuela en la promoción de los aprendizajes necesarios para saber convivir con los demás, por lo que se debe favorecer la visión de una sociedad inclusiva y que promueva la tolerancia como elemento vital en la conformación de una sociedad democrática.

La convivencia democrática constituye una forma de vida que posibilita espacios para todos los ciudadanos mediante mecanismos de participación y representación, los cuales potencializan la construcción y transformación de la sociedad; en suma, se trata de una experiencia cotidiana de vivencia (Luengo y Moreno, 2006). Entretanto, la Organización para la Cooperación y el Desarrollo Económicos (OCDE) y el Gobierno español (MEC, 2005), citados por Gros y Contreras (2006, p. 105), reconocen que el aprendizaje para el ejercicio ciudadano se configura como un conjunto de competencias claves para el desarrollo educativo en los próximos años. Por tal motivo, es pertinente considerar las siguientes categorías para orientar la formación de competencias ciudadanas en contextos educativos:

- Conocimiento y comprensión de la realidad social en que se vive y ejerce la ciudadanía democrática, a través de la incorporación de formas de comportamiento individual que capaciten a las personas para convivir en una sociedad cada vez más plural, relacionándose con los demás, cooperando, comprometiéndose y afrontando conflictos.

- Habilidades para la plena participación del ciudadano contemporáneo en aspectos fundamentales de la vida cívica, como la participación política, social y económica.

- Valoración de la pluralidad, diversidad y participación del «otro» como elementos claves para la convivencia democrática en la vida moderna. 
A partir de esta perspectiva, es necesario planificar el currículo desde la comunión y articulación de conocimientos sobre contenidos políticos, las formas de participación ciudadana, las habilidades y destrezas para vivir en una sociedad. De tal manera, se pretende que esto se exprese en el accionar diario del estudiante en el contexto democrático; es decir, que en este proceso cognitivo se integran los diferentes tipos de aprendizaje ciudadano para pensar, hablar, tomar decisiones, relacionarse con sus pares y comportarse en la sociedad. Al respecto, Ruiz y Chaux (2005) aportan la siguiente clasificación de competencias ciudadanas:

- Conocimientos: se refiere a la información que los estudiantes deben saber y comprender acerca del ejercicio ciudadano.

- Competencias cognitivas: es la percepción que el ciudadano tiene de las diferentes situaciones y contextos en los que se desenvuelve.

- Competencias emocionales: son las capacidades para identificar y generar respuestas constructivas ante las emociones y el entorno.

- Competencias comunicacionales: son las habilidades para establecer relaciones de diálogo constructivo con otras personas.

- Competencias integradoras: todas las competencias anteriores se articulan en la acción de un espacio concreto.

La dinámica operativa de estas competencias se puede observar con mayor detalle en la figura 1:

Figura 1

Dimensiones fundamentales para la acción ciudadana

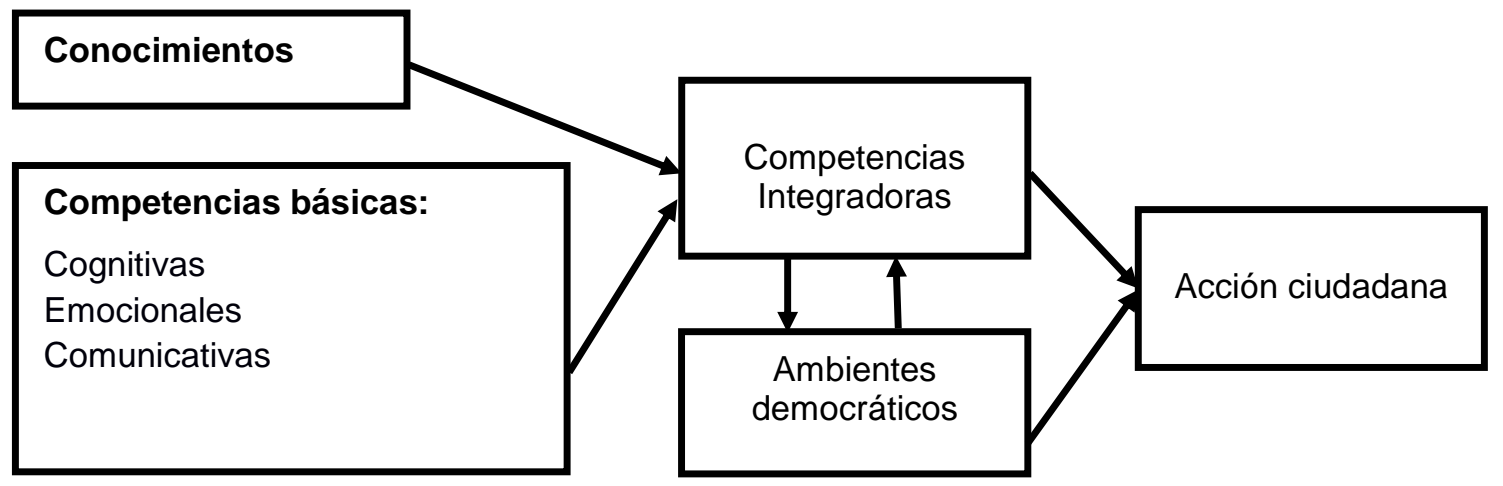

Fuente: Ruiz y Chauz, 2005 p. 33. 
La clasificación descrita en la Figura 1 permite tener una postura integradora de los aprendizajes ciudadanos. Destaca como punto de partida del aprendizaje la adquisición del conocimiento en el estudiantado para el ejercicio ciudadano; igualmente, plantea competencias cognitivas y emocionales, ambas referidas a procesos mentales y de percepción, lo que favorece el desarrollo personal y la convivencia en sociedad. Del mismo modo, propone la competencia comunicacional como una alternativa para la resolución de problemas; finalmente, propone una competencia integradora que propicia la interacción permanente de los componentes anteriores en los entornos democráticos.

\section{Abordaje de las competencias ciudadanas desde el programa de estudio de Educación Cívica 2009}

La implementación, desde el año 2009, del programa de estudio de Educación Cívica, enfocado en el proyecto "Ética, estética y ciudadanía" para el Tercer Ciclo y el Ciclo Diversificado, con el fin de mejorar las capacidades para la convivencia y fortalecer la ciudadanía joven en el estudiantado. El Ministerio de Educación Pública mediante la implementación de este programa de estudio busca la formación de personas que desarrollen criterio y juicio político ante el sistema democrático, se informen, expresen sus opiniones mediante la deliberación y sepan ponderarlas para el logro de consensos y disensos, favorecer la participación organizada y la actuación constructiva para la solución de los problemas colectivos. La promoción de estas competencias ciudadanas en el sistema escolar fortalece el desarrollo de una democracia más profunda y sostenible (MEP, 2009).

Como enfoque curricular de este programa de estudio se establece el constructivismo donde la persona joven es el centro del proceso de aprendizaje, el estudiante es el gestor y constructor de su propio conocimiento, el cual se desarrolla de forma gradual a partir de la realidad social y la contextualización del contenido. Además, el enfoque se complementa con aspectos importantes de otras corrientes como socio-reconstruccionismo y el constructivismo social. Asimismo, la estrategia pedagógica propuesta se fundamenta en el "aprender haciendo" y el "aprender a aprender", los aprendizajes se abordan desde la comprensión de los contenidos curriculares conceptuales, procedimentales y actitudinales de forma activa, creativa, democrática, integradora y flexible. (MEP, 2009).

El conocimiento en esta propuesta curricular es prominente porque refiere a la información que el estudiantado posee y requiere para el accionar ciudadano; por ejemplo, 
conocimientos básicos como: características del sistema político costarricense, el proceso electoral, las funciones de las instituciones del Estado, la legislación vigente, las prácticas y actitudes democráticas, entre otros. La promoción de estos aprendizajes ciudadanos se desarrolla por medio de la participación en talleres y el desarrollo de proyectos, estos son comprendidos como espacios donde el estudiante acciona y robustece los conocimientos y habilidades para el mejoramiento de las capacidades necesarias para el saber ser y el saber convivir en sociedad. Este tipo de aprendizajes para la ciudadanía y la democracia se obtienen en la práctica, estas estrategias se hacen operativas mediante la acción grupal que activa el pensamiento por propia convicción y facilita la construcción de conocimiento.

Las competencias ciudadanas se desarrollan en el programa de estudio de Educación Cívica vigente desde tres líneas de acción: una primera, desde lo conceptual, que propone una temática referida a este tópico explícitamente como un contenido curricular ubicado en la segunda unidad de undécimo año: "Las personas jóvenes como ciudadanos y ciudadanas fortalecemos actitudes y prácticas democráticas"; esta desarrolla en el aula mediante el contenido procedimental "fortalecimiento de la deliberación y la negociación colaborativa para promover la formación ciudadana acorde con el régimen democrático y su funcionamiento". La segunda línea, desde la transversalidad de los contenidos curriculares; y, por último, una tercera línea dimensional que se explicita en toda la reforma educativa contemplan aprendizajes direccionados a mejorar los procesos de convivencia del estudiantado en los espacios escolares, familiares y sociales; al incentivar la participación activa de la ciudadanía joven en los contextos democráticos.

Las competencias ciudadanas propuestas en el programa de estudio de Educación Cívica se subdividen en dos áreas, la primera corresponde a aprendizajes para el fortalecimiento del sistema político democrático, para esto se promueve la formación en competencias como la participación, la representación, la comunicación social y política y el sentido de comunidad; y otra área para promocionar aprendizajes para la toma de decisiones, la resolución alternativa de los conflictos, la disminución de la violencia y las buenas relaciones sociales para la convivencia, esta segunda área se favorece mediante el abordaje de la negociación colaborativa, la deliberación, los consensos y el manejo de los disensos (MEP,2019).

El componente integrador está presente de manera dinámica y constante en el desarrollo de los aprendizajes ciudadanos propuestos en la dimensión de competencias del 
programa de Educación Cívica, lo que muestra una conexión directa entre los componentes cognitivos, emocionales, comunicacionales y el complemento conceptual (Tabla 1).

Tabla 1 Dimensión de competencias ciudadanas del programa de Educación Cívica 2009

\begin{tabular}{|c|c|}
\hline Competencias & Aprendizajes Integrales \\
\hline \begin{tabular}{llll} 
Negociación & para & \multicolumn{1}{l}{ lograr } \\
concesos y & manejar & los \\
disensos. & & & \\
\end{tabular} & $\begin{array}{l}\text { - } \quad \text { Saber darse a entender. } \\
\text { - } \quad \text { Saber escuchar y desarrollar la disposición a cambiar opiniones. } \\
\text { - } \quad \text { Saber discriminar, en las posiciones propias, lo más relevante y } \\
\text { - } \quad \text { Saber cuándo se pueden tomar las decisiones por consenso y } \\
\text { - } \quad \text { por medio de cuáles mecanismos. } \\
\text { - de revisión. } \\
\text { - Tener aprecio hacia el gradualismo. } \\
\text { - Saber desarrollar liderazaos democráticos. }\end{array}$ \\
\hline $\begin{array}{l}\text { Participación y representación } \\
\text { para poder incidir en las } \\
\text { decisiones colectivas. }\end{array}$ & $\begin{array}{l}\text { - } \quad \text { Apreciar los espacios de participación. } \\
\text { - } \quad \text { Tener capacidad de participar y delegar. } \\
\text { - } \quad \text { Relacionarse con reciprocidad, respeto y lealtad. } \\
\text { - } \quad \text { Usar los espacios de organización para enfrentar los problemas. } \\
\text { - } \quad \text { cuantas vertical y horizontal. } \\
\text { - } \quad \text { conocer el sistema político costarricense, sus instancias de } \\
\quad \text { participación y representación y ser capaz de incidir en este. }\end{array}$ \\
\hline $\begin{array}{l}\text { Deliberación con sentido de } \\
\text { comunidad para ser capaces } \\
\text { de expresar articuladamente } \\
\text { las ideas, partiendo no solo del } \\
\text { individuo, sino también del } \\
\text { colectivo. }\end{array}$ & $\begin{array}{l}\text { - Desarrollar la capacidad de formar criterio y contrastarlo con } \\
\text { - } \quad \text { Saber opiniones. } \\
\text { - Saber escuchar y desarrollar la disposición a cambiar opiniones. } \\
\text { - } \quad \text { Participar o delegar sobre la base del buen juicio. } \\
\text { - Desarrollar la tolerancia, el respecto y el disfrute hacia lo } \\
\text { diferente. }\end{array}$ \\
\hline
\end{tabular}

Comunicación social y política para eliminar el analfabetismo en este campo.
- Alfabetización en comunicación social y política al realizar una lectura crítica de la forma y el mensaje.

- Analizar los discursos clásicos, anuncios especiales, espacios noticiosos, datos y entrevistas.

- Analizar los principales medios usados por la juventud: televisión, internet, juegos de video, cultura virtual entre otros

- Tener conocimiento de la opinión pública y el uso de las encuestas.

Fuente: MEP, 2009, pp. 33-34.

La tabla 1 presenta esta dimensión en los programas de Educación Cívica 2009, mediante una serie de aprendizajes ciudadanos divididos y categorizados en cuatro 
competencias que el estudiantado debe adquirir para desempeñarse en el ejercicio democrático; se espera, de tal forma, que esto aborde integralmente todo el currículo de la asignatura, desde el nivel de sétimo año hasta alcanzar los contenidos curriculares propuestos para los niveles superiores del Ciclo Diversificado.

Este análisis de la dimensión de competencias pretende lograr un acercamiento a la clasificación de componentes ciudadanos planteados por Ruiz y Chaux, así como generar insumos que permitan al profesorado la comprensión de cada uno de los aprendizajes propuestos para alcanzar cada competencia. En esta línea, Zabala y Arnau subrayan que,

(...) enseñar competencias implica utilizar formas de enseñanza consistentes en dar respuestas a situaciones, conflictos y problemas cercanos a la vida real en un complejo proceso de construcción personal con ejercitaciones de progresiva dificultad y ayudas contingentes según las características diferenciales del alumnado. (2007, p. 15)

La necesidad permanente y prioritaria del sistema educativo de formar ciudadanos para la vida en democracia y el estricto apego a lo establecido en la Ley Fundamental de Educación en su artículo $2^{\circ}$ inciso $\mathrm{c}$ al señalar que como uno de sus fines "formar ciudadanos para una democracia en que se concilien los intereses del individuo con los de la comunidad", dio como resultado una postura curricular muy actual y pertinente de formación en competencias ciudadanas en la asignatura de Educación Cívica, esto permite desarrollar prácticas educativas con sentido de integralidad que favorece la formación del estudiantado con capacidades para fortalecer el sistema político costarricense y con capacidades para vivir y convivir en sociedad.

\section{Reflexiones finales}

Existe una concordancia teórica entre lo presentado en el programa de estudio de Educación Cívica del 2009 y los documentos sobre las competencias ciudadanas que formaron parte de la revisión bibliográfica de este ensayo. Además, existe coherencia en la forma en que se propone el desarrollo de los procesos de aprendizaje para vivir y convivir; igualmente, se favorece el planteamiento de actividades didácticas muy participativas que presentan retos constantes para el estudiantado.

Las actividades de mediación en el aula constituyen el elemento curricular adecuado para desarrollar el aprendizaje, la práctica y la evaluación de las competencias ciudadanas, 
mediante procesos dinámicos que propicien la interacción del estudiantado en la resolución de problemas y respuestas a situaciones concretas. Por ello, los procesos de aprendizaje deben ser creativos, flexibles y contextualizados a las necesidades del estudiantado.

Asimismo, se destaca la comparación que se realiza entre la dimensión de las competencias del programa de Cívica y la propuesta sobre componentes ciudadanos presentada por Ruiz y Chaux (2005), porque permite visualizar de forma integrada las habilidades que debe manifestar el ser humano para poder desempeñarse satisfactoriamente en los espacios democráticos.

En relación con el diseño de las unidades didácticas, el programa de estudio se estructura bajo el formato del currículo de competencias, lo que favorece procesos de aprendizaje integrales, mediante el abordaje de los contenidos curriculares desde lo conceptual, procedimental y actitudinal. Sin embargo, es necesario destacar que, aunque el diseño se estructura para el desarrollo explícito de competencias, estas se desarrollan en el currículo operativo de manera transversal, por lo que permean los contenidos propuestos en los diferentes niveles y que se evidencian en la cotidianidad del aula.

Es destacable el rol y la responsabilidad del profesorado de Educación Cívica en el aprendizaje significativo de las competencias ciudadanas, pues debe propiciar los momentos importantes que posibiliten el ejercicio ciudadano a través del abordaje de los contenidos curriculares propuestos en el programa de estudio. De igual modo, debe fomentar procesos de aprendizaje que favorezcan las habilidades comunicacionales, lo cual solo es posible mediante una capacitación docente que brinde insumos para desarrollar este tipo de mediación didáctica.

Las lecciones de Educación Cívica en los centros educativos son insuficientes para lograr el aprendizaje de las competencias ciudadanas en el estudiantado. La formación para la ciudadanía es un asunto del currículo nacional básico, porque busca orientar hacia una educación que propicie calidad de vida. En síntesis, es necesario que las competencias ciudadanas se desarrollen en todas las asignaturas para impactar de forma sustancial la educación costarricense y promover aprendizajes para saber vivir y convivir. La formación integral del estudiantado es una responsabilidad que todos los profesionales de la educación deben asumir con Costa Rica y con las próximas generaciones. 


\section{Referencias}

Argudín Vásquez, Yolanda. (2005). Educación Basada en competencias: Nociones y antecedentes. México: Editorial Trillas S.A.

Alfaro Valverde, Alicia y Badilla Vargas, Maynor. (2007). La educación ciudadana en Costa Rica: una perspectiva pedagógica y didáctica intercultural. Revista Pensamiento Actual, 7(8-9), 31-45. Recuperado de https://revistas.ucr.ac.cr/index.php/pensamientoactual/article/view/4096/3923

Alfaro Valverde, Alicia y Badilla Vargas, Maynor. (2010). La educación para la ciudadanía: un componente esencial en la formación universitaria costarricense. Inter Sedes, 10(18), $12-40$.

Recuperado https://revistas.ucr.ac.cr/index.php/intersedes/article/viewFile/1024/1085

Andrade Cázares, Rocío. (2005). Un acercamiento al enfoque por competencias profesionales. México: Universidad de Guanajuato / Universidad Marista de Querétaro

Arce Ramírez, Henry y Cheves Ponce, Florlenis. (2016). Perspectivas pedagógica, epistemológica y metodológica del programa de estudios de la asignatura de Educación Cívica en Costa Rica. Revista Electrónica Educare, 20(1). Recuperado de http://www.redalyc.org/pdf/1941/194143011024.pdf

Asociación Internacional para la Evaluación del Logro Educativo. (2011). Informe Latinoamericano del ICCS 2009, Actitudes y conocimientos cívicos de estudiantes de secundaria en seis países de América Latina. Recuperado de https://iccs.acer.org/files/Informe Espanol Modulo Latinoamericano ICCS 2009.pdf

Centro de Estudios y Publicaciones. (2003). Participación Ciudadana para el fortalecimiento de la Democracia. San José, Costa Rica: Centro de Estudios y Publicaciones Alforja.

Cortina Orts, Adela. (2001) Ciudadanía política: del hombre político al hombre legal. Madrid, España: Alianza Editorial, S. A.

Delors, Jacques. (1996). La educación encierra un tesoro. México: Ediciones UNESCO.

Dengo Obregón, María. (2006). Educación Costarricense. San José, Costa Rica: Editorial UNED.

Escámez Sánchez, Juan y Gil Martínez, Ramón. (2002). La educación de la ciudadanía. Madrid, España: Editorial CCS-ICCE.

Eurydice. (2011). Educación para la ciudadanía en Europa, Consejo y Parlamento Europeo. Recuperado de http://eacea.ec.europa.eu/education/eurydice/documents/thematic reports/139ES HI.pdf

García Fraile, Juan y Saban Vera, Carmen. (2008). Un nuevo modelo de formación para el siglo XXI: La enseñanza basada en competencias. España: Editorial Davinci Continental. S.L. 
García Retana, José. (2011). Modelo educativo basado en competencias: importancia y necesidad. Revista Actualidades investigativas en Educación, 11(3), 1-24 Recuperado de http://www.redalyc.org/pdf/447/44722178014.pdf

Gimeno, Consuelo y Henríquez, Argentina. (2001). Hacia una conceptualización de ciudadanía crítica y su formación. Anuario Pedagógico. Centro de Investigación Poveda. Recuperado https://www.centropoveda.org/IMG/pdf/conceptualizacionciudadania.pdf

Guillen Gaytan, Amalia, Sáenz López, Karla, Badii Hosein, Mohammad y Castillo Villareal, Jorge. (2009) Origen, espacio y niveles de participación ciudadana. Daena: International Journal of Good Conscience. 4(1), 179-193. Recuperado de http://www.spentamexico.org/v4-n1/4(1)\%20179-193.pdf

Gros Salvat, Begoña y Contreras Guzmán, David. (2006). La alfabetización digital y el desarrollo de competencias ciudadanas. Revista iberoamericana de educación, (42), 103-125. Recuperado de https://rieoei.org/historico/documentos/rie42a06.htm

Instituto de Formación y Estudios en Democracia del Tribunal Supremo de Elecciones. (2012). Democracia y ciudadanía actica: valores y práctica. Instituto de Formación y Estudios en Democracia, Tribunal Supremo de Elecciones. San José, Costa Rica. Recuperado de http://www.tse.go.cr/pdf/fasciculos capacitacion/democracia-yciudadania-activa-valores-y-practicas.pdf

Luengo Horcajo, Florencio y Moreno Olmedilla, Juan. (2006). Modelo de Convivencia Democrática y Comunitaria. Convivencia en la Escuela, 1(6), 1-8. Recuperado de https://www.researchgate.net/publication/308971448 Modelo de Convivencia Democr atica y Comunitaria Los diez ambitos de mejora

Magenzo Kolstrein, Abraham y Arias Albañil, Rafael. (2015). Informe Regional: Educación Ciudadana y Formación docente en países de América Latina. Recuperado de https://www. oas.org/cotep/GetAttach.aspx?lang=en\&cld=304\&aid=489

Ministerio de Educación Pública de Costa Rica. (2005). Programa de Estudio de Educación Cívica. San José, Costa Rica: MEP.

Ministerio de Educación Pública de Costa Rica. (2009). Programa de Estudio de Educación Cívica, Proyecto Ética, Estética y Ciudadanía. San José, Costa Rica: MEP. Recuperado de

http://cse.go.cr/sites/default/files/acuerdos/educacion civica iii ciclo y educacion dive rsificada.pdf

Ministerio de Educación Pública. (2009). Programa de Estudio de la Especialidad de Diseño Publicitario. San José, Costa Rica: MEP. Recuperado de https://www.mep.go.cr/sites/default/files/programadeestudio/programas/dise\%C3\%B10publicitario-12.pdf

Ministerio de Educación Nacional de Colombia. (2011). Orientaciones para la Institucionalización de las Competencias Ciudadanas, Cartilla 1 Brújula. Recuperado de https://www.mineducacion.gov.co/1759/articles-235147 archivo pdf cartilla1.pdf 
Ministerio de Educación Nacional. (2004). Formar para la ciudadanía si es posible. Colombia: Editorial Revolución Educativa Colombia aprende. Recuperado de https://www.mineducacion.gov.co/1621/articles-116042 archivo pdf4.pdf

Ministerio de Educación de Chile. (2003). Educación Cívica y el ejercicio de la ciudadanía, Los estudiantes chilenos en el estudio internacional de Educación Cívica. Recuperado de http://www.oei.es/quipu/chile/eval civica.pdf

Murillo Castaño, Gabriel y Castañeda Aponte, Nathalia. (2007). Construcción de la ciudadanía juvenil. Revista del CLAD Reforma y Democracia, (37), 1-17. Recuperado de http://www.redalyc.org/pdf/3575/357533669005.pdf

Niño Rojas, Víctor. (2008), Competencias en la Comunicación (2da Ed.). Bogotá, Colombia: ECO EDICIONES.

Organización de las Naciones Unidas para la Educación, la Ciencia y la Cultura. (2009). Competencias ciudadanas para la Sociedad del Siglo XXI, Las Tecnologías de la Información y la Comunicación en el aula, Uruguay: Plan CEIBAL - MEC.

Palacios Robles, María. (2005). Formación del ciudadano costarricense de 1821-1886. San José, Costa Rica: Editorial UCR.

Rosales López, Carlos. (2009). Hacia una ciudadanía inclusiva. ¿Un reto a la complejidad educativa? Revista Educación Inclusiva, 2. Recuperado de http://www.revistaeducacioninclusiva.es/index.php/REl/article/view/45/41

Ruiz Silva, Alexander y Chaux Torres, Enrique. (2005). La formación de competencias ciudadanas: Bógota: Editorial Ascofade. Recuperado de https://laasociacion.files.wordpress.com/2015/11/la-formacion-de-competenciasciudadanas.pdf

Tobón, Tobón, Sergio. (2007). El enfoque complejo de las competencias y el diseño curricular por ciclos propedéuticos. Revista Asociación Pedagógica, 16, 14-28. Recuperado de https://dialnet.unirioja.es/servlet/articulo?codigo $=2968540$

Trejos Salas, Gerardo y May Cantillo, Hubert. (2001). Constitución y democracia costarricense. San José, Costa Rica: Editorial Juricentro.

Vargas-Cullell, Jorge; Roxero-Bixby, Luis y Seligson, Mitchel A. (2006). Cultura política de la democracia en Costa Rica: 2006. San José, Costa Rica: Centro Centroamericano de Población, Universidad de Costa Rica. Recuperado de http://www.kerwa.ucr.ac.cr/handle/10669/75347?show=full

Villarini Jusino, Ángel. (1996). Currículo Orientado al Desarrollo Humano Integral. Biblioteca del pensamiento crítico. San Juan, Puerto Rico.

Zabala Vidiella, Antoni y Arnau Belmonte, Laia. (2007). Cómo aprender y enseñar competencias. Barcelona, España: Editorial GRAÓ. 
Revista indizada en

sciplo redalyc. latindex

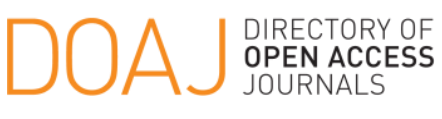

Distribuida en las bases de datos:

- Dialnet

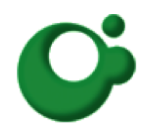
SHERPA/RøMEO REDIB

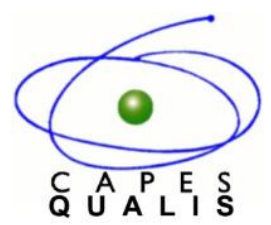

MIAR 